\title{
The transparent discolored glass for industrial and high-speed transport
}

\author{
Regina Khazhiakhmetova ${ }^{1, *}$ Indira Kashuba ${ }^{2}$, Svetlana Vlasova ${ }^{1}$, Fyodor Kapustin ${ }^{1}$, and \\ Rudolf $\mathrm{Hela}^{3}$ \\ ${ }^{1}$ Ural Federal University named after the first President of Russia B. N. Yeltsin, Institute of New \\ Materials and Technologies, 620032 Yekaterinburg, Russia \\ ${ }^{2}$ Ural Federal University named after the first President of Russia B. N. Yeltsin, Educational \\ Department, 620032 Yekaterinburg, Russia \\ ${ }^{3}$ Institut of Technology of Buiding Materials and Components, 60200 Brno, Czech Republic
}

\begin{abstract}
Glasses for transport and test cabins are synthesized from various batches of raw materials with an equivalent addition of complexing discolourers. The effect of cerium oxide and potassium nitrate on the properties of silicate glasses is studied. Measurement of the optical characteristics of glasses shows that the light transmittance increases to 90$93 \%(\lambda=500-750 \mathrm{Nm})$, and there is no image distortion. In addition, it was found that the introduction of additional additives to the charge in the case of each specific composition leads to an increase in hydrolytic stability and mechanical strength, which is important for transport engineering.
\end{abstract}

\section{Introduction}

Requirements for the quality of glass are constantly growing. The light transmission of windscreens and glass, through which is decolorized the forward visibility for the driver must be sufficiently high. In addition, windshields must be more mechanically strong and resistant to impact than conventional window glass. To achieve stable characteristic, it is necessary to use high-quality raw materials for glassmaking. We suggest using some additives in the standard composition of the charge to obtain a colorless translucent glass melt, which will be used to make high-strength transport glass.

The use of raw materials from the Ural region in glass production will reduce transport costs and, accordingly, reduce the cost of raw materials, if the quality of the final product is maintained. In the mass production of glass products, you can use inexpensive raw materials with an iron content of up to 0.2 with subsequent enrichment. Iron oxides are actively involved in chemical processes in the production of industrial glass. It is known how important the role of the redox potential (ORP) of the charge is [1-3], changes in the equilibrium of iron oxide towards the oxide form (III), which less intensively colors the glass. This can be achieved by oxidation in the synthesis process: introduce additional oxygen-containing components-discolourers. Currently, cobalt oxide and selenium are used

\footnotetext{
* Corresponding author: r.f.khazhiakhmetova@urfu.ru
} 
in production to produce colorless industrial glass. Both agents are physical discolourers that reduce the transmittance and, to some extent, the performance properties of glass [1].

The purpose of this work is to study the possibility of obtaining high-quality glass mass, discolored with special additives. Such glass can be used to produce ultra-transparent glass for use in mechanical engineering: for ultra-high-speed transport, for obtaining glass that can withstand heavy loads.

\section{Methodology}

In this work, we used a number of traditional physical and chemical research methods and techniques set out in regulatory documents. The properties of synthesized materials were measured on the research and laboratory equipment of the Ural Federal University and the Institutes of the Ural Branch of the Russian Academy of Sciences, they are the following: light transmittance by a Shimadzu UV-2600 spectrophotometer (the Centre for Collective Use "Spectroscopy and Analysis of Organic Compounds"), water resistance by Standard 10134.1-82, crystallization ability by the method of stable temperature drop, TCLE measurement by the quartz dilatometer DIL $402 \mathrm{C}$.

\section{Results and discussion}

The main raw materials for the input of silicon, calcium and magnesium oxides were taken from the Ural deposits. Their chemical composition is shown in Table 1. The samples were synthesized in laboratory furnaces with silite heaters in corundum crucibles. During synthesis, the charge was kept at a temperature of $1450{ }^{\circ} \mathrm{C}$ for 3 hours. After obtaining a homogeneous melt, the amount of more than 10 pieces were cast in the form of a flat round plate, after which they were annealed in a muffle furnace at 560-570 ${ }^{\circ} \mathrm{C}$. Samples of rectangular glass in the amount of 38 PCs. They were cut, sanded and polished, and had plane-parallel surfaces with a thickness of $4 \mathrm{~mm}$.

Table 1. Chemical composition of raw materials, wt. \%.

\begin{tabular}{|l|c|c|c|c|c|c|c|c|c|}
\hline Type of raw material & $\mathrm{SiO}_{2}$ & $\mathrm{Al}_{2} \mathrm{O}_{3}$ & $\mathrm{CaO}$ & $\mathrm{MgO}$ & $\mathrm{Na}_{2} \mathrm{O}$ & $\mathrm{K}_{2} \mathrm{O}$ & $\mathrm{SO}_{3}$ & $\mathrm{Fe}_{2} \mathrm{O}_{3}$ & Other \\
\hline $\begin{array}{l}\text { Quartz sand Kamensk- } \\
\text { Uralskoe field }\end{array}$ & 98.52 & 0.61 & 0.17 & 0.04 & 0.05 & 0.14 & - & 0.19 & 0.28 \\
\hline $\begin{array}{l}\text { Quartz sand Butkinskoe } \\
\text { field }\end{array}$ & 96.78 & 1.43 & 0.13 & 0.33 & 0.38 & 0.60 & - & 0.15 & 0.20 \\
\hline $\begin{array}{l}\text { Dolomite } \\
\text { Sukhorechenskoye field }\end{array}$ & 1.00 & 1.00 & 33.60 & 18.20 & - & - & - & 0.20 & 54.00 \\
\hline $\begin{array}{l}\text { Limestone Sosnovskoye } \\
\text { field }\end{array}$ & 0.70 & 1.03 & 54.20 & - & - & - & - & 0.12 & 43.95 \\
\hline
\end{tabular}

All synthesized samples had a clear blue tint. The physical and chemical properties of glasses are measured: TCLE (temperature coefficient of linear expansion), water resistance and crystallization ability of glasses. The TCLE of all investigated glasses is $90 \cdot 10^{-7}{ }^{\circ} \mathrm{C}^{-1}$. All glasses are to 4 class water resistance. The glass samples were not crystallized.

It has been established that the change in the light transmission of colorless glass and the disruption of the stability of the technological process is due to the total iron content [4-6], the equilibrium state of Fe (II) $\leftrightarrow$ Fe (III). The course of the reaction in the glass mass is affected by the oxidation-reduction conditions (ORC) of the glass melting process. 
In the work it was found out that the ORC depends on the following parameters: ORP, bivalent iron fraction, thermal transparency index and basicity index [6].

ORP is estimated by reduction number $(\mathrm{RN})$ :

$$
R N=\sum Y_{i} \cdot P_{i}^{\prime}
$$

$Y_{i}$ — carbon number of the i-component of the charge;

$P_{i}^{\prime}$-mass of the i-component per $2000 \mathrm{~kg}$ of sand.

The Fe (II) fraction (dFe(II)) is determined by the spectral method (from the transmission curve) and is calculated by formula:

$$
d F e(I I)=\frac{\lg \tau_{\lambda}}{L W \rho \chi \lambda_{F e^{2+}}}
$$

where $\tau_{\lambda}$ - the spectral transmittance of the sample at a wavelength $\lambda=1000 \mathrm{~nm}$;

$L$-sample thickness, cm;

$W$-mass content of iron in glass in terms of metal, \%;

$\rho$-density of glass, $\mathrm{g} / \mathrm{cm}^{3}$;

$\chi \lambda_{\mathrm{Fe}^{2+}}$-volume absorbance of bivalent iron, calculated at a concentration of $102 \mathrm{~g} / \mathrm{cm}^{3}$ glass (at a wavelength of $1000 \mathrm{~nm}$, it is equal to $3.60 \mathrm{~cm}^{2} / \mathrm{g}$ ).

An important indicator for glasses is the thermal transparency index (TTI) of the glass mass, determined in the infrared region of the spectrum at a wavelength of $1100 \mathrm{~nm}$ and calculated by the formula:

$$
T T I=4.0^{-1} \cdot \tau_{1100}
$$

where $\tau_{1100}$ - light transmittance of a sample with a thickness of $0.004 \mathrm{~m}$ at a wavelength of $1100 \mathrm{~nm}$.

Table 2 shows some characteristics of some glasses and the composition of discolourers. Cerium oxide and potassium nitrate were added to the charge in various proportions to create an oxidizing medium. Composition 1 is a glass synthesized on nonenriched quartz Sands, it is given for comparison.

Table 2. The composition of the discolourers and some characteristics of the glass samples.

\begin{tabular}{|l|c|c|c|c|c|c|}
\hline & \multicolumn{2}{|c|}{ Mass content of discolourers, \% } & \multirow{2}{*}{$\mathrm{Fe}_{2} \mathrm{O}_{3}$} & \multirow{2}{*}{ ORP } & \multirow{2}{*}{$\mathrm{dFe}$ (II) } & \multirow{2}{*}{ TTI } \\
\cline { 2 - 3 } & $\mathrm{CeO}_{2}$ & $\mathrm{~K}_{2} \mathrm{O}$ & & & & \\
\hline $\mathbf{1}$ & - & - & 0.63 & 13.47 & 21.20 & 5.90 \\
\hline $\mathbf{2}$ & - & - & 0.43 & 11.00 & 9.72 & 7.86 \\
\hline $\mathbf{7}$ & 0.15 & 1.00 & & 40.34 & 3.35 & 9.20 \\
\hline $\mathbf{8}$ & 0.15 & 2.00 & & 50.90 & 5.14 & 8.80 \\
\hline $\mathbf{1 3}$ & 1.00 & 1.00 & & 70.12 & 4.27 & 8.99 \\
\hline $\mathbf{1 4}$ & 1.00 & 2.00 & & 80.74 & 3.13 & 8.85 \\
\hline
\end{tabular}

It is shown that the values of $\mathrm{dFe}$ (II) in investigated glasses decrease with the addition of decolorizing agents from 26.28 to $3.13 \%$. On the base of the ORP result assessment the color and tinge of glass are predicted at the stage of batch preparation. In the glass charge the ORP changes to +80.74 , the overlapping of blue and yellow is observed that gives 
different tinge of green since iron in the glass is present simultaneously in the form of $\mathrm{Fe}^{2+}$ and $\mathrm{Fe}^{3+}$, the oxide form predominates.

Figure 1 shows the spectral characteristics of glasses with various additives. Analysis of the obtained curves shows that for industrial glass synthesized without discolourers, low light transmission is observed in the visible region, starting from $550 \mathrm{~nm}$. This indicates that they contain a significant amount of iron in the form of $\mathrm{Fe}^{2+}$.

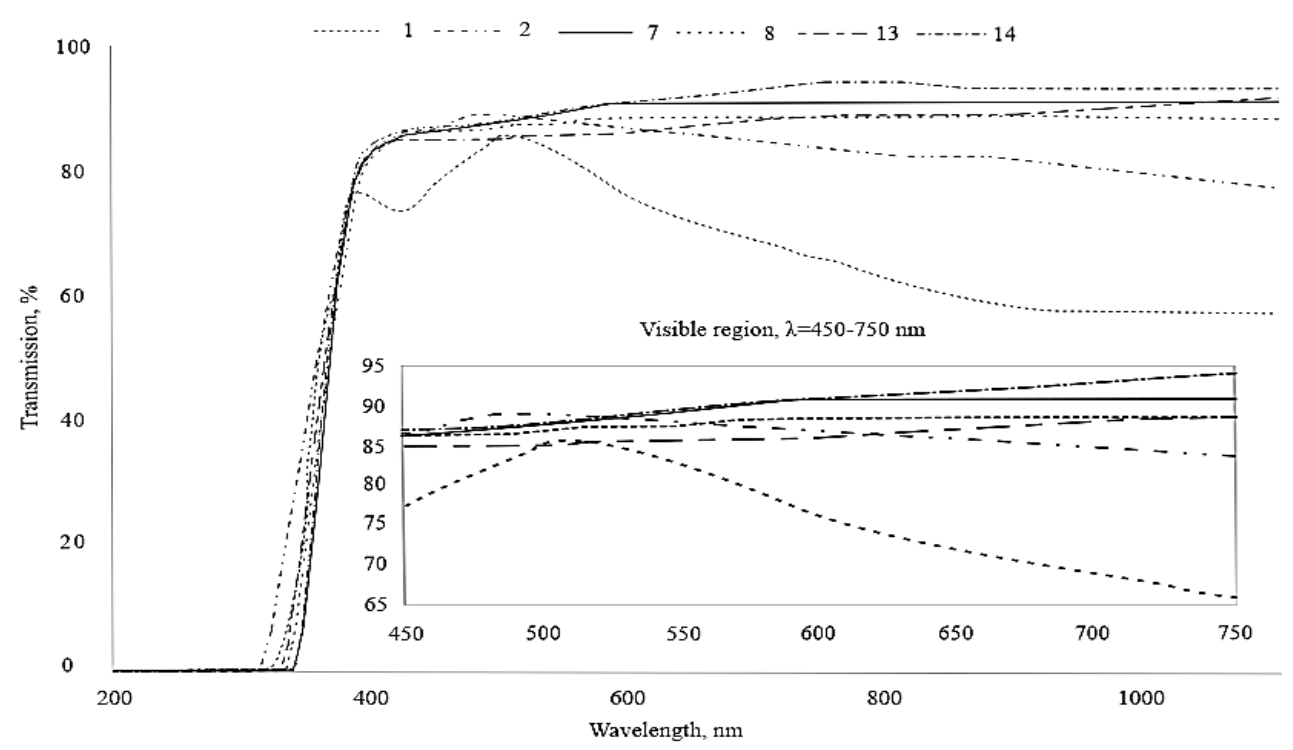

Fig. 1. Spectral curves of the glass transmission of the samples No 1, 2, 7, 8, 13, 14 .

The curves of the basicity index dependence on the content of the $\mathrm{K}_{2} \mathrm{O}-\mathrm{CeO}_{2}$ system discolourers were also plotted (Figure 2). The glass basicity index $\mathrm{Fe}_{2+} \cdot 100 / \mathrm{Fe}_{\text {total }}, \%[7,8]$ is a criterion for evaluating the redox state of glass mass.

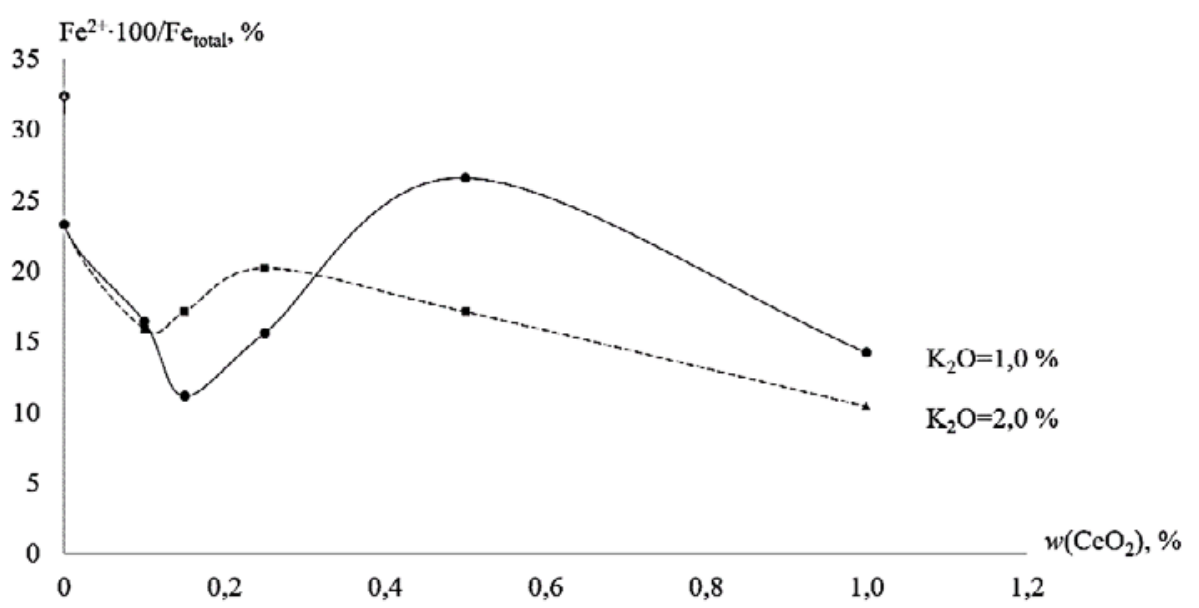

Fig. 2. The change in the ratio of iron oxides to the content of cerium dioxide forsheet glass.

It is shown that the number of discolourers depends on the chemical composition of the charge, on the content of iron oxide in the glass. Glasses with a basicity index of more than $18 \%$ are classified as not discoloured. If the index is less than $18 \%$, it is difficult to 
bediscoloured. The recommended composition for the synthesis of transport glasses is shown in Table 3.

Table 3. Recommended composition of glass, wt. \%.

\begin{tabular}{|l|c|c|c|c|c|c|c|l|}
\hline Glass & $\mathrm{SiO}_{2}$ & $\mathrm{Al}_{2} \mathrm{O}_{3}$ & $\mathrm{CaO}$ & $\mathrm{MgO}$ & $\mathrm{Na}_{2} \mathrm{O}$ & $\mathrm{K}_{2} \mathrm{O}$ & $\mathrm{SO}_{3}$ & $\mathrm{CeO}_{2}$ \\
\hline Construction & 72.45 & 1.60 & 8.50 & 3.50 & 12.50 & 1.00 & 0.30 & 0.15 \\
\hline
\end{tabular}

\section{Conclusion}

The effect of the amount of discolourers on the ORP, physical and chemical properties and spectral characteristics of glasses was studied.

To increase the redox potential and the optical characteristics of the glass, it is recommended to use $\mathrm{CeO}_{2}$ and $\mathrm{K}_{2} \mathrm{O}$ as discolourers. With a minimum content of $\mathrm{CeO}_{2}=$ $0.1 \%$ and $\mathrm{K}_{2} \mathrm{O}=1.0 \%$ and an unchanged temperature of the melting of sheet glass, light transmission in the visible region of the spectrum increases from 84 to $89 \%$, and at a maximum $\mathrm{CeO}_{2}=1 \%$ and $\mathrm{K}_{2} \mathrm{O}=2 \%$ increases to $91.7 \%$. The creation of an oxidizing environment allows you to stabilize the level of thermal transparency of the melt.

By of TTI, you can adjust the charge recipe individually for each industrial production system, which will allow you to control the glassmaking mode and get high-quality glass at the output.

A corrected composition of ultra -transparent sheet glass that can be used for transport is proposed: mechanical strength and chemical stability are increased by increasing the content of aluminum oxide, the presence of cerium oxide, and partial replacement of sodium oxide with potassium oxide, followed by quenching after synthesis.

\section{References}

1. Guloyan Yu A 2003 Technology of glass and glassware (Vladimir: Transit-X ) p 480

2. Levitin L Ya, Litvin V I, Tokarev V D, Yachevskii A V 2012 Increase of glass manufacturing efficiency using cullet in float-glass production J. Steklo and Ceramics 69 pp 143-145

3. Fedorova V A 2010 Modern problems of obtaining high-transparency glasses $J$. Steklo and Ceramics 67 pp 82-85

4. Atkarskaya A B, Zaitseva M I 2005 Redox Equilibrium of Iron in Silicate Glasses $J$. Steklo and Ceramics 62 pp 304-307

5. Kiyan V I, Atkarskaya A B 2006 Dynamics of the redox state of the melt in the continuous production of clear glass J. Steklo and Ceramics 63 pp 249-253

6. Fedorova V A 2000 Combined Evaluation of the Role of Impurities and Small Additives in Glass Production J. Steklo and Ceramics 57 pp 272-274

7. Zhernovaya N V, Min'ko N I, Onishchuk V I, Mel'nikova L I 2000 Effect of the redox potential of the glass batch and cullet on the tinting of industrially produced glass containing iron oxides J. Steklo and Ceramics $\mathbf{5 7}$ pp 84-86

8. Agureev S A, Levitin L Ya, Tokarev V D 2014 Efficient Control Regimes for the Thermal and Technological Process of Glassmaking in Tank Furnaces for Float-Glass Production J. Steklo and Ceramics 70 pp 347-349 